\title{
Self-Sustainable Energy Efficient Long Range WiFi Network for Rural Communities
}

\author{
Khairuddin Ab-Hamid ${ }^{1}$, Chong Eng Tan ${ }^{2}$, Sei Ping Lau ${ }^{3}$ \\ Faculty of Computer Science and Information Technology \\ Universiti Malaysia Sarawak (UNIMAS) \\ 94300 Kota Samarahan, Malaysia. \\ khair@cans.unimas.my ${ }^{1}$, cetan@fit.unimas.my ${ }^{2}$, splau@fit.unimas.my ${ }^{3}$
}

\begin{abstract}
WiFi is a cost effective technology of choice for network extension in the rural areas. The telecentre network can reach further to the nearby villages within $10 \mathrm{~km}$ radius by the use of long range WiFi relay points. The challenges encountered will be the self-sustainability of the network. It should be highly energy efficient and to be powered by the very limited energy sources available in the rural environment. In this case, a modular solar based power supply system has been investigated and enhanced to achieve longer operating hours for equipment installed in the middle of the tropical rainforest and on top of a mountain. The overall design of the self-sustainable long range WiFi network model and the end-user wireless terminal shall also meet the conditions of the rural as well as the living pattern of the local people. The proposed network model has been successfully deployed in a remote village in Borneo, named Bario, connecting six nearby villages to the telecentre for Internet access.
\end{abstract}

Index Terms-Long range WiFi, self-sustainable network, rural connectivity, energy efficient solar power supply

\section{INTRODUCTION}

Bridging the digital divide has been the development agenda of the Malaysian government for many years. However, it has been a very challenging task due to the remoteness of the rural communities. Telecentre development programmes have been initiated as one of the important strategies in bridging the digital divide across the country where more than 2000 telecentres have been setup to date [12] The rural environment may lack of basic utilities such as electricity supply from the power grid that would cause a lot of the equipment designed for urban applications may not be practical to use in the rural environment. Some rural areas are very remote where they are only accessible by restricted means of transportation and some even take very long traveling time to reach. Bario, a remote village located at the interior of Sarawak state in Malaysia is a good example where it can only be accessed via lightweight aircraft before the year 2010. Now it is accessible via the muddy logging road cutting across thick jungle which could take more than 12 hours to arrive from the nearest urban town, and again the accessibility to Bario via road is seriously depending on the condition of the logging road.

The Malaysian government's pilot project on bridging the digital divide in Bario, known as the eBario project, was implemented by the Centre of Excellence for Rural Informatics (CoERI) from Universiti Malaysia Sarawak
(UNIMAS) has been started in 1999. The project has enabled Internet access to one of the most remote community in Malaysia since then. The eBario telecentre has been built and equipped with satellite connectivity via the Very Small Aperture Terminal (VSAT) system, has created a gateway to reach the outside world for the people of Bario. Ever since then, the local people can communicate with the rest of the world via telephone calls and the Internet.

However, the telecentre in Bario only act as a centrally located Internet access centre for users from nearby villages. In order to use the telecommunication services provided at the telecentre, it requires a lot of courage and motivation from the villagers as they have to travel from a few kilometers to tens of kilometers or spend one to two hours of traveling time just to reach the telecentre. The cost of the telecentre deployment is high hence it is not cost effective and impossible to deploy additional telecentres that are relatively closer to each other. Owing to this constraint, there is a need for the telecentre to reach out further to other villages to bring more impacts on the services it offers.

Our research team took the courage to bring the initiative of bridging the digital divide into the next level where we proposed a self-sustainable energy efficient long range WiFi network model to connect nearby villages within $10 \mathrm{~km}$ radius of distance from the telecentre. The aim of this project is to design a cost effective, self-sustainable and energy efficient long range WiFi network that can be easily deployed in remote locations for the purpose of extending the Internet access network of the telecentre. The wireless network will be able to overcome the difficulties of laying cable across mountains and thick jungles easily. The proposed long range WiFi network model has been designed based on the rural environment constraints and has been implemented successfully in extending the eBario telecentre's connectivity. The entire wireless network operation has been self-sustained via the green energy initiative, in this case, the solar energy. Our proposed self-sustainable long range WiFi network has extended its connectivity to six nearby villages in Bario since 2010.

\section{BACKGROUND}

There are many promising network technologies being implemented in the urban to provide network connectivity. However, the networking technologies such as optical fiber 